\title{
ECOPHENOTYPIC AND GEOGRAPHIC CONSTRAINTS IN A MICROEVOLUTIONARY STUDY OF A RHABDOMESID BRYOZOAN
}

HAGEMAN, Steven J., Dept. of Geology, University of Illinois, 1301 W. Green St., Urbana, IL 61801 U.S.A.

Documentation of microevolutionary changes in morphologic character complexes through geologic time, especially across speciation events, is one of the most significant contributions that paleontologists can provide to evolutionary biology. Papers treating patterns of evolution have established criteria required for the study of microevolution, which include: wide geographic coverage, a sequence of closely spaced samples, well defined taxa and rigorous biometric testing of large samples. Many excellent empirical studies of microevolution have taken great steps to maximize temporal resolution and to improve numerical treatment of data. Factors of ecophenotypic and geographic variation, however, have been neglected in most microevolutionary studies.

Late Paleozoic cyclothems of the North American midcontinent, with their fine stratigraphic resolution and well documented paleoenvironments that can be correlated over large geographic distances, provide a unique opportunity to study patterns of microevolution and concomitant ecophenotypic and geographic variation. Bryozoans are well suited for studies that require large morphometric data sets, because of their relative abundance, complexity, and the fact that fragmentary material can provide tenable data. Due to their colonial nature, limits of phenotypic versus genotypic variation.

In order determine the effects of geographic variation among the rhabdomesid genus Streblotrypa (Cryptostomata, Bryozoa), specimens were collected from nine localities, all taken from the lowermost six inches of the Winzeler Shale (Virgilian) distributed along a $300 \mathrm{~km}$ transect from south-central Kansas to northeastern Kansas. Data were collected from five specimens per locality, all from nearly identical paleoenvironments, and of very nearly the same age. Cluster analysis and discriminant analysis demonstrate some differences among the groups, however, no morphologic trends are found to correspond to geographic distributions, nor can specimens be readily assigned to locality based on morphology.

A strong genetic control within colonies is apparent. Individual observations (composite OTU's) can be assigned to the specimen from which they were measured with a very high degree of confidence. Variation between environments at the same locality over the shortest possible time span (estimated in the magnitude of $10^{4}$ years) is currently being tested by analyzing data collected from the next unit above, a limestone with interbedded shales. Data from three other localities of similar environment, but significantly different age ( $+3 \mathrm{Ma})$, are also being analyzed to further test the degree of morphologic variation with environment verses time.

Results obtained using standard multivariate techniques applied to morphometric data are building a composite picture of the characteristics of microevolutionary change within Streblotrypa. 